\title{
PRECEDING PHONOLOGICAL CONTEXT EFFECTS ON PALATALIZATION IN BRAZILIAN PORTUGUESE/ENGLISH INTERPHONOLOGY
}

\author{
Melissa Bettoni-Techio \\ Rosana Denise Koerich \\ Universidade Federal de Santa Catarina
}

\section{Abstract}

This article reports a study investigating the effects of the preceding context on palatalization of word-final alveolar stops by Brazilian learners of English. Thirty learners with 150 hours of formal instruction in English read a sentence list in the FL including 240 tokens of final alveolar stops in different preceding and following context combinations. The hypothesis investigated was that high vowels and rising diphthongs in the preceding context would cause more palatalization than mid and low vowels due to carryover effects from vowels to the target sound. The hypothesis was supported. A hierarchy of difficulty concerning preceding phonological contexts was established from the results. The combination of preceding and following phonological contexts was also investigated.

Keywords: palatalization, interphonology, phonological context. 


\section{Introduction}

In general, phonologists and phoneticians agree that a universal principle of sound systems is that sound units are influenced by their adjacent elements, assuming different phonetic values, according to processes such as assimilation, elision, liaison, and epenthesis (Jackson, 1980; Laver, 1994; Wolfram \& Johnson, 1982). Bearing in mind the claim that interlanguages undergo the same phonological processes of natural languages (Eckman, 1991), the above statement can be considered to be true for interlanguages as well.

In Brazil, research has investigated the change of features of wordfinal consonants in Brazilian Portuguese (BP)/English interphonology concerning phonological context (e.g., Kluge, 2004). Owing to the fact that English syllable structure is more complex than that of $\mathrm{BP}$, allowing words to end in obstruents, for example, BP learners tend to add an epenthetic vowel to a final obstruent, turning CVC syllables into CV.CV sequences as shown by Baptista and Silva Filho (1997), Koerich (2006), and Silveira (2004). Personal experience as EFL learners and teachers allows us to state that in the case of alveolar stops BP learners may also produce palatalization or even palatalization with paragoge. For instance, paragoge and palatalization may be found in the production of loanwords such as notebook, which may be pronounced by Brazilians as [noutebuki], [noutibuki], or [noutfibuki] according to dialect.

Since in $\mathrm{BP} / \mathrm{t} /$ and $/ \mathrm{d} /$ vary according to the following phonological context, that is, /t/ and / d / undergo palatalization as a non-distinctive geographical dialect marker when preceding high front vowels (Hooper, 1976; Silveira, 1986; Monaretto, Quednau, \& Hora, 1999; Albano, 1999, 2001; Cristófaro Silva, 2002) and transfer this process to loanwords, the process is expected to be present in the English interphonology of BP learners as well.

Bettoni-Techio and Koerich (2006) proposed a hierarchy for the triggering of palatalization by following phonological contexts. The authors found that the high front vowel was not amongst the most problematic contexts as would be expected from transfer. The present 
study, in turn, aims at verifying the influence of the preceding context by investigating how the combination of preceding and following contexts might affect palatalization. This study was strongly motivated by the belief that the establishment of hierarchies of difficulty is of great importance for designing pronunciation teaching or training materials as well as instruments for future research in interphonology.

\section{The phonological context and Brazilian Portuguese/ English interphonology}

BP learners of English tend to palatalize final alveolar stops even when this process is not allowed by the phonotactics of English. This can be explained based on Lado (1957, as cited in Eckman \& Iverson, 1993) when he argues that the splitting of two native language allophones into separate phonemes would represent maximum difficulty in L2 pronunciation. Bettoni-Techio and Koerich (2006) showed that even though palatalization is frequent in BP/English interphonology, the contexts triggering it are not those expected from transfer. An approximate hierarchy of following contexts considering palatalization triggers - from the most difficult to the least difficult was drawn from Bettoni-Techio and Koerich's results:

$$
\begin{aligned}
& / \mathrm{f}>\mathrm{k}>\text { silence }>\mathrm{v}>\mathrm{p}>\mathrm{0}>\mathrm{g}>\mathrm{n}>\mathrm{h}>\mathrm{m}>\mathrm{d} 3 \\
& >\mathrm{t}>\mathrm{b}>\mathrm{i}>\mathrm{d}>\mathrm{l}>\mathrm{t} \int>\varepsilon>\mathrm{z}>\mathrm{s} /
\end{aligned}
$$

Few studies have tested the effects of the preceding context on the production of codas. Yavas (1994), for instance, found that preceding high vowels favored voicing of final stops, Hansen (2001) found that whereas diphthongs and / $\mathrm{o}$ strongly disfavored target-like production of final codas, a preceding monophthong other than / $/$ / slightly favored it, and Kluge (2004) found that, amongst the contexts tested, / $\Lambda$ / was the preceding context which most frequently disfavored target-like production of word-final nasals. 
The present study investigated the influence of the preceding context in terms of a carryover process. Carryover and anticipatory effects, resulting from the coarticulation of neighboring sounds, have been investigated in native language VCV sequences (e.g., Recasens, 1987; Farnetani \& Recasens, 1993; Marchal \& Hardcastle, 1993; Modarresi, Sussman, Lindblom, \& Burlingame, 2004). A carryover effect comprises the effect the articulation of a sound has on the following sound, whereas an anticipatory effect is the effect the articulation of a sound has on its preceding sound. In a $\mathrm{V}_{1} \mathrm{CV}_{2}$ sequence a "variety of transitional phenomena" can be observed: (a) vowel to vowel effects, (b) vowel to consonant effects, and (c) consonant to vowel effects (March \& Hardcastle, 1993, p. 139).

Modarresi et al. (2004) investigated the production of V.CV and VC.V syllables by five speakers of English and found that in both open and closed syllables carryover effects predominated in alveolar contexts. In summary, the authors say that (a) consonants are more sensitive to vowel coarticulation (tongue dorsum displacement) in syllable-final position than in syllable-initial position (e.g., / $t$ / is more affected in the word net than in the word ten); (b) carryover effects tend to be greater than anticipatory effects when the target is a final stop; and (3) closed syllables particularly promote carryover effects (e.g., in the word feet, the effects from $/ \mathrm{f} /$ to $/ \mathrm{i} /$ to $/ \mathrm{t} /$ are greater than the effects from / t / to / $i /$ to / f /) (p. 298).

Concerning palatals, the fricatives are considered high consonants (Giegerich, 1992), and palatographic configurations have shown that affricates are even higher than fricatives (Recasens, 1990). Having this body of research and assumptions in mind, it is expected that learners who produce palatalization when aiming at the production of a final alveolar stop may do so more often when the alveolar stop is preceded by a high vowel because the height of the vowel will carry over raising the consonant so as to approximate it to the palate.

Since no studies investigating the effect of the preceding context on final oral stops in BP/English interphonology have been found, this 
study seems to be of great importance to the field. Considering that the constraints which hold for natural languages also hold for interlanguages, the present study aims at investigating carryover effects (preceding context effects) regarding palatalization of the final alveolar stops in BP/English interphonology.

\section{Method}

The present study aimed at answering the question of whether the preceding context influences the occurrence of palatalization of final alveolar stops. The hypothesis triggering the study was that high vowels and rising diphthongs as preceding contexts of word-final alveolar stops tend to cause more palatalization than mid and low vowels.

The participants of the study were thirty pre-intermediate students of English (approximately 150 hours of previous instruction), fifteen male and fifteen female, with ages ranging from 15 to 47 years, enrolled in the third semester of an English course. The choice for preintermediate learners was motivated by (a) the belief that mispronunciations need to be dealt with in early stages of language learning and (b) the necessity of having participants who were not complete beginners and thus could cope with the data gathering procedures.

Two instruments were designed for data collection: (a) a participant profile questionnaire applied to assess biographical information as well as information on factors relevant to phonological research, such as amount of instruction and use of language learning strategies outside the classroom; and (b) a sentence reading test in English, designed to assess the production of final alveolar stops (see sample in Appendix A).

The test consisted of a list of 240 topically unconnected short sentences containing monosyllabic words ending in $/ t /$ or $/ d /$ in different preceding and following phonological context combinations. The preceding contexts tested were $/ i, \varepsilon, \alpha / \partial^{1}, a I, \Lambda, o v /$. The vowels / I, U, æ, U/ were not included to limit the number of tokens 
as well as to have the same number of (a) high and mid-high (/ $i, \mathrm{aI}, \mathrm{ou} /)$, and (b) mid-low and low vowels $(/ \varepsilon, a / \supset, \Lambda /)$. The diphthong /eI/ was not included because the great majority of monosyllabic words containing / e I / are spelled with a final ' $\mathrm{e}$ ', and since the data gathering instrument - a reading test - involved orthographic input, the inclusion of $C^{\prime} \mathrm{e}^{\prime}$ words could compromise the data by L1 transfer, since in BP words final ' $\mathrm{e}$ ' is fully realized. Consonants were not included as preceding contexts in order to limit the study to singleton codas. The following contexts tested consisted of the vowels $/ i, \varepsilon, o /$, the consonants $/ p, b, t, d, k, g, f, v$, $\mathrm{s}, \mathrm{z}, \mathrm{t} \int, \mathrm{d} 3, \mathrm{~h}, \mathrm{l}, \mathrm{m}, \mathrm{n} /$, and silence. The limitation in terms of vowels was due to the fact that the quality of the vowels was not being tested. It was essential to include the high front vowel / i/ since, in BP, palatalization is triggered by its presence in the following context of an alveolar stop. The other two vowels, / $\varepsilon$ / and / o / were included in order to provide both a front and a back vowel as following context. The interdental fricatives $/ \theta, \delta /$ and the glides $/ j, w /$ were not included because they are frequently mispronounced by BP EFL learners. Also, / $/$ / was not tested because its voiced counterpart /Z/ appears in the onset in only a very limited number of loan words. The sentences were randomized for presentation, so that each participant read them in a different order, ensuring the absence of ordering effects.

Participants volunteered for the study and were not aware of its specific objective, only that the study concerned BP/English interphonology. The data gathering session was held in the foreign language laboratory at the university where the course was offered during regular class hours. First, participants answered the profile questionnaire and then were instructed for the subsequent English test, which took 20 minutes. The equipment used for the recording consisted of two consoles (Sony model LLC4500MKII), twenty cassette tape recorders (Sony model ER5030), and head-mounted microphones (Sony model HS95). The written and oral instructions about the questionnaire and the test were given in Portuguese. 
3.1 Speech production data treatment and judgment procedures

The recordings were digitized at $22.05 \mathrm{kHz}$ using the Cool Edit software, converted into mono to facilitate the subsequent acoustic analysis, and filtered to improve sound quality. Then, the spectrogram settings of Praat were altered to $10000 \mathrm{~Hz}$ and the formant settings were altered to show maximum formant at $9500 \mathrm{~Hz}$ in order to enable the researcher to deal with the fricative portion of palatalized alveolar stops.

In order to classify each target as palatalized or not palatalized, the researcher carried out a triangular analysis to the tokens of final alveolar stops by listening to the recordings, and analyzing the sound waves and the spectrograms. Among other advantages, the use of Praat allowed for the isolation of the target and for the measurement of formants and pause duration between the target and the following sounds. Figure 1 and Figure 2 show samples of palatalization of final / $\mathrm{t}, \mathrm{d} /$.

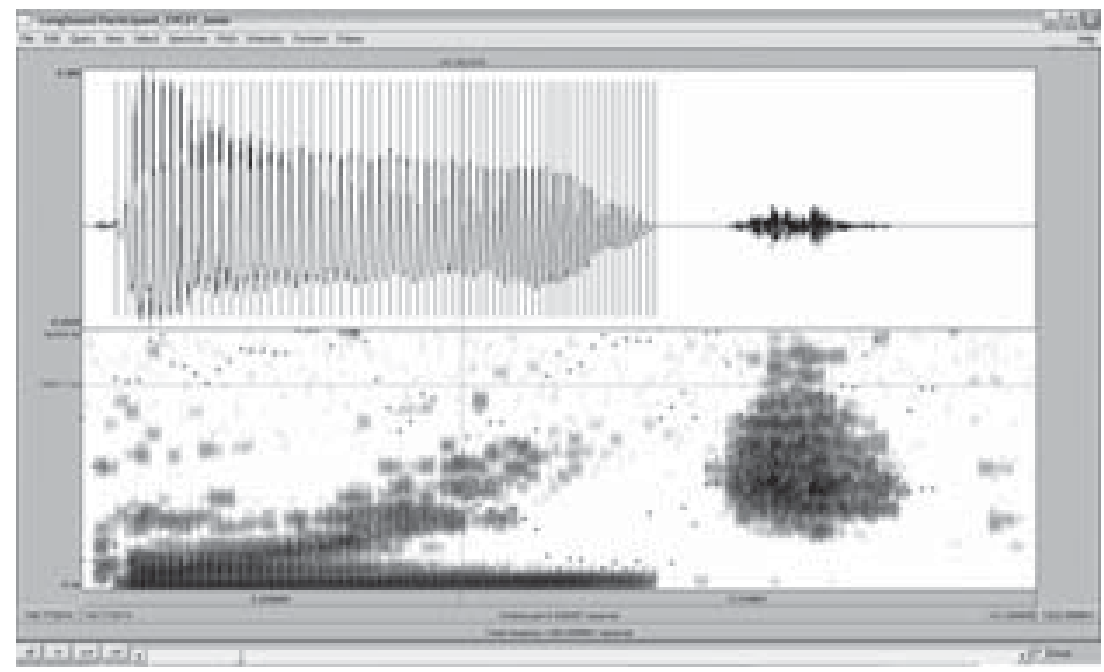

Figure 1./t $\int /$ in the realization [poit $\left.\int\right]$. 


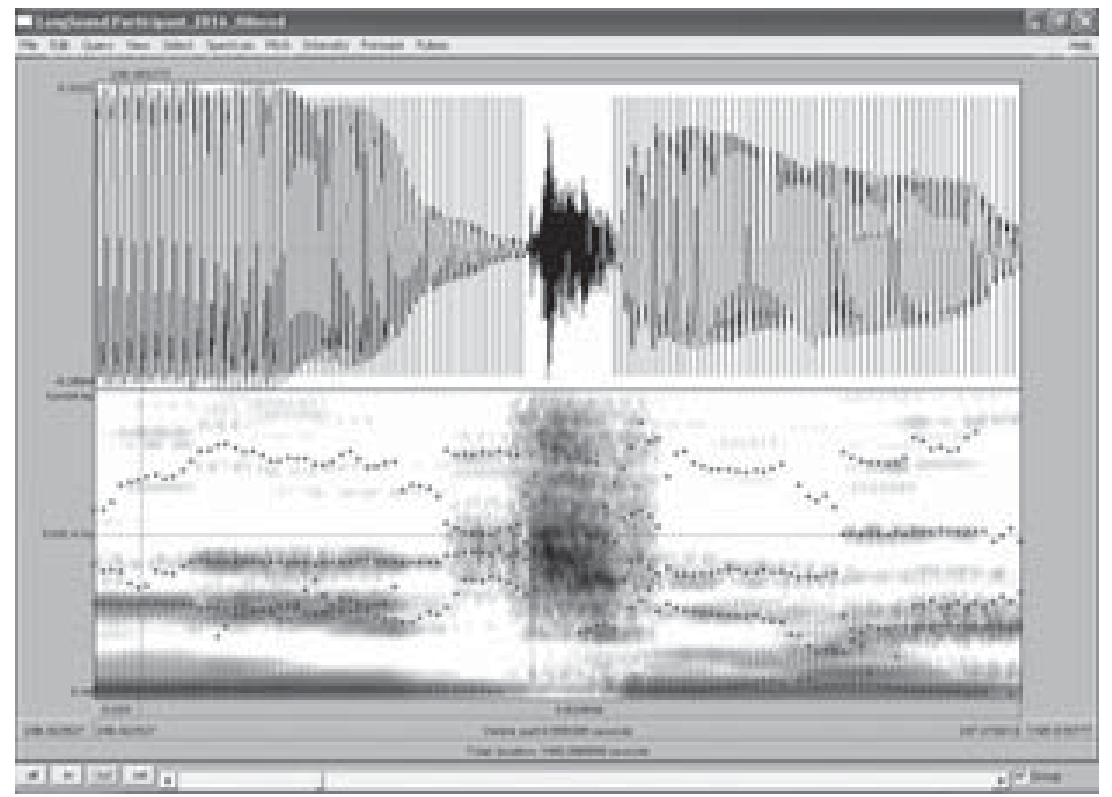

Figure 2. /d3/ in the realization [nidzma I].

The productions where the preceding or the following context was mispronounced by the participants (e.g. [rod saIn] for 'road sign'), or where there was a pause longer than $0.35 \mathrm{~s}$ between the target and following sound were discarded. Thus, of the 7,200 tokens tested ( 240 for each of the 30 subjects), 5,618 were left for statistical analysis. That is, of the 3,600 tokens produced when the target was /t/, 799 were discarded, and of the 3,600 produced when the target was /d/, 783 were discarded.

The statistical analysis of the data was carried out using the SPSS software. Wilcoxon Signed Ranks Tests were run with the intent of verifying if two variables - each pair of preceding/following context triggered different mispronunciations. 


\section{Results and discussion}

As mentioned above, few studies have investigated the effects of the preceding context on the production of final codas (e.g., Yavas, 1994; Hansen , 2001) . Coarticulation studies on first language have found evidence of carryover effects from vowels to consonants in closed syllables. High vowels are articulated closer to the palate than non-high vowels; thus, it was hypothesized that palatalization would be more frequent when the consonant is preceded by a high than by a non-high vowel. The present study tested three 'high' vowels (one high, one mid-high, and one low-high diphthong - /i, oU, aI /) and three non-high vowels $(/ \mathrm{A}, \mathrm{E}, \Lambda /$ ) before each target-following context combination. Even though / aI/ and / oU/ are not considered high vowels, at the end of their articulation the tongue is high, therefore, for the purposes of the present study, they were treated as high vowels. Table 1 presents the descriptive statistics for high and non-high vowels:

\section{Table 1}

Rates of palatalization by preceding context (high $\mathrm{x}$ non-high vowels)

\begin{tabular}{lllll}
\hline Context & N & Palatalized & Rate & SD \\
\hline high & 2,902 & 404 & $14 \%$ & .16 \\
non-high & 2,716 & 200 & $7.36 \%$ & .14 \\
Total & 5,618 & 604 & $10.75 \%$ & - \\
\hline
\end{tabular}

A Wilcoxon Signed Ranks Test ran on the rates of palatalization computed by subjects for high and non-high preceding vowels showed a highly significant difference $(p<.0001): Z=-4.465$. This result supported the hypothesis formulated in this study that high vowels and closing diphthongs in the preceding context would cause more palatalization than mid and low vowels. The data for each individual vowel is presented in Table 2 . 


\section{Table 2}

Rates of palatalization by preceding context

\begin{tabular}{lllll}
\hline Context & N & Palatalized & Rate & SD \\
\hline al & 978 & 115 & $11.7 \%$ & .13 \\
i & 1067 & 138 & $12.9 \%$ & .15 \\
oU & 857 & 154 & $18 \%$ & .23 \\
E & 959 & 60 & $6.2 \%$ & .14 \\
A o & 878 & 63 & $7.1 \%$ & .12 \\
$\Lambda$ & 879 & 74 & $8.4 \%$ & .18 \\
Total & 5,618 & 604 & $10.7 \%$ & - \\
\hline
\end{tabular}

Wilcoxon Signed Ranks Tests showed that palatalization was significantly more frequent when word-final alveolar stops were preceded by /oU/. The results for the pairs $/ 0 /$ and the other high vowels are the following: For /oU/-/i/, $Z=2.07, p=.039$, and for / oU/ $-/ \mathrm{al} /, Z=2.50, p=.012$. The results for the Wilcoxon tests for $/ \mathrm{oU} /$ and the non-high vowels were statistically significant $(p<.0001)$ as well. Among the low vowels there was no significant difference. Therefore the following hierarchy of palatalization promoters may be proposed in relation to the preceding context from the most difficult to the least difficult one: / ov >i, aI $>\Lambda, o / \alpha, \varepsilon /$. Laver (1994) states that the rounding of / ov/ requires either horizontal lip contraction alone, or horizontal and vertical lip contraction, triggering change in the area and shape of the interlabial space. Also, rounding adds strength to the vowel (Hooper, 1976). It can be speculated that besides tongue position, lip rounding is also carried over to the following $[t, d]$ in a way that the compressed air produced at the medial phase of the articulation of $[t, d]$ may be released with more friction, inducing more to palatalization than either /aI/ or / $i /$. Moreover, protrusion or lip rounding is characteristic of the articulation of affricates. Also, considering the hierarchy of difficulty posed by the following context proposed by Bettoni-Techio and Koerich (2006), /o / was the most problematic vowel and was also the only rounded vowel tested. In the case of /aI/ and / $i /$, the higher 
frequency of palatalization was predicted by the hypothesis in terms of carryover effects of vowel height.

\subsection{Combinations of preceding and following contexts}

The results of the statistical tests seem to indicate the influence of the preceding context on the production of final alveolar stops. Along with the hierarchy of following contexts proposed by Bettoni-Techio and Koerich (2006), the hierarchy of preceding contexts found in the present study points to an effect of preceding and following context combinations. In order to illustrate the effect of combinations of preceding and following contexts, Table 3 presents the frequencies of palatalization for the combination of the most problematic preceding and following contexts with the least problematic preceding and following contexts for a few tokens. The table comprises the combinations: (1) the most problematic preceding and following contexts; (2) the most problematic preceding and least problematic following context; (3) the least problematic preceding and most problematic following context; and finally, (4) the least problematic preceding and least problematic following context.

\section{Table 3}

Rates of palatalization by combination of preceding and following contexts according to difficulty

\begin{tabular}{llllll}
\hline Context & Target & $\mathbf{N}$ & Palatalized & Rate & Token \\
\hline$(1) / \mathrm{O} /-/ \mathrm{f} /$ & $\mathrm{t}$ & 25 & 10 & $40 \%$ & boat fever \\
$(1) / \mathrm{O} /-/ \mathrm{f} /$ & $\mathrm{d}$ & 23 & 7 & $30 \%$ & road forks \\
$(2) / \mathrm{O} /-/ \mathrm{S} /$ & $\mathrm{t}$ & 24 & 1 & $4 \%$ & boat sank \\
$(2) / \mathrm{O} / / \mathrm{S} /$ & $\mathrm{d}$ & 24 & 1 & $4 \%$ & road sign \\
$(3) / \mathrm{E} / / \mathrm{f} /$ & $\mathrm{t}$ & 24 & 1 & $4 \%$ & bet fifteen \\
$(3) / \mathrm{E} / \mathrm{f} /$ & $\mathrm{d}$ & 28 & 3 & $10 \%$ & red feathers \\
$(4) / \mathrm{E} /-\mathrm{S} /$ & $\mathrm{t}$ & 29 & 0 & $0 \%$ & pet sings \\
$(4) / \mathrm{E} /-/ \mathrm{S} /$ & $\mathrm{d}$ & 26 & 0 & $0 \%$ & red socks \\
\hline
\end{tabular}


Besides confirming that problematic contexts in combination may trigger more palatalization than problematic contexts combined with nonproblematic contexts, the table also shows that palatalization is not word specific ${ }^{2}$. Thus, familiarity and frequency of use had less influence on word production than phonological context. For example, the words 'boat', 'road', and 'red' which were combined with both most and least problematic following contexts had the following frequencies of palatalization: 'boat' - was palatalized $40 \%$ of the time when followed by

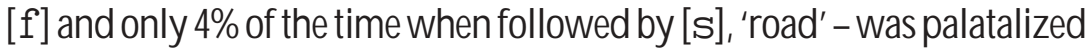
$30 \%$ of the time when followed by [f] and only $4 \%$ of the time when followed by [s], and 'red' - was palatalized $10 \%$ of the time when followed by [f] and was not palatalized when followed by [s]. This line of results seems to indicate that familiarity with the word did not lead participants to mispronounce or accurately pronounce them since the frequencies varied according to the difficulty posed by the phonological context.

One last analysis on the combination of preceding and following phonological contexts was carried out for preceding /oU/ and following $/ \mathrm{o} /$ to illustrate effects of adjacent rounding on production of the voiceless final alveolar stop. For comparison, $/ \mathrm{g} /$ was used in the following context because there were no significant differences between rate of palatalization between $/ \mathrm{o} /$ and $/ \mathrm{g} /$ considering all preceding contexts tested, and / $\mathrm{i}$ / was used for comparison because it is considered a natural promoter of palatalization. Table 4 displays the data.

\section{Table 4}

Rates of palatalization by combination of preceding / $\mathrm{O} /$ and following $/ \mathrm{o} /, / \mathrm{g} /$, and /i/

\begin{tabular}{llllll}
\hline Context & Target & $\mathbf{N}$ & Palatalized & Rate & Token \\
\hline /oU/-/o/ & $\mathrm{t}$ & 23 & 13 & $56 \%$ & coat or \\
/oU/-/g/ & $\mathrm{t}$ & 25 & 8 & $32 \%$ & boat goes \\
/oU/-/i/ & $\mathrm{t}$ & 11 & 1 & $9 \%$ & goat eats \\
\hline
\end{tabular}

Note: $\mathrm{N}$ comprises the total number of realizations with each type of context 
By the analysis of the context combinations presented, it can be inferred that rounding in both preceding and following contexts is even more problematic than the combination of the most problematic preceding with the most problematic following context - / oU/ and / f/ - as shown in Table 3. It is also more problematic than when /oU/ is combined with another context with similar rates of overall palatalization $(/ \mathrm{g} /)$, and more problematic than /oU/ combined with a high front vowel $(/ \mathrm{i} /)$ which is claimed to induce palatalization in several dialects in $\mathrm{BP}$.

\section{Conclusion}

The main objective of the present study was to investigate the effects of the preceding context on final alveolar stop production by Brazilian learners of English in order to contribute to the design of training material. The hypothesis addressed in the present study concerned the effects the preceding context may have on the production of final alveolar stops in BP/English interphonology concerning palatalization. It was shown that high vowels favor the palatalization of final $/ \mathrm{t} /$ or $/ \mathrm{d} /$. Moreover, /oU/ was shown to be the most problematic preceding context tested. A possible explanation is that besides height, / oU/ and affricates resulting from palatalized alveolar stops share lip rounding, thus, increasing the number of articulatory features that can be carried over to final alveolar stops, consequently promoting their palatalization.

The main findings and suggestions of this investigation with BP learners of English are summarized below.

Finding 1: High, mid-high vowels, and rising diphthongs in the preceding context of final alveolar stops cause more palatalization than mid-low and low vowels.

Finding 2: The round vowel /oU/ in the preceding context of final alveolar stops causes more palatalization than any other vowels tested. 
Finding 3: Preceding and following problematic contexts in combination trigger more palatalization than when one of the contexts is not or is less problematic.

Finding 4: Palatalization seems not to be word specific but context dependent.

Suggestion 1: From findings 1, 2, and 3 - Perceptual training tasks should be designed so as to present combinations of preceding nonhigh vowels and following /s/ in the beginning of the task and gradually increase difficulty by controlling the combinations untill preceding / ov / and following / $/$ are presented.

Suggestion 2: From finding 4 - Perceptual training tasks may not need to present various words to increase variability, but the target sounds must be embedded in various contexts. The finding showed that patterns can be drawn from interphonology by analyzing variables of phonological context, which answers our research question and confirms our hypothesis. Based on these findings, suggestions for the design of perceptual training tasks were provided. Thus, the objectives of the present research were fulfilled since an opportunity for a better understanding of the production of final alveolar stops in Brazilian Portuguese/English interphonology was achieved.

Even though learners' dialect was shown in previous studies to interfere in the acquisition of L2 sound systems, the present study has shown that dialect is just one of the factors responsible for the development of interphonologies. Bettoni-Techio, Rauber and Koerich (2007), for instance, found a relationship between perception and production of final alveolar stops concerning paragoge, aspiration and palatalization according to voicing of the target sound, and BettoniTechio (2005) showed that sonority relations across syllables tend to have a slight effect on production of final alveolar stops. Thus, among other factors, phonological contexts interact with transfer and universals in the process of second language acquisition.

It is important for teachers and material designers to be attentive to possible errors that may appear during the process of learning. Many 
errors can be prevented instead of corrected. Palatalization may be predicted by native language dialect as shown in Bettoni-Techio and Koerich (2006) and the occurrence of palatalization is dependent on phonological context. In the case of final alveolar stops this can be done by teaching final alveolar stops in context. It is helpful to instruct learners on linking and deletion and to introduce easier contexts such as preceding / $\varepsilon /$ and following / $/$ / before more difficult contexts such as preceding high vowels and following / $\mathrm{f} /$. The hierarchies of phonological context presented here can also be used as a basis for the design of perceptual training tasks including the fading technique, as in Bettoni-Techio and Koerich (2008). Unveiling the patterns of error production can increase the chances for success in the processes of teaching and learning a new phonological system.

An important limitation of the present study concerns the sounds selected as preceding contexts. As no previous studies had been carried out concerning final alveolar stops, phonological context, and palatalization in BP/English interphonology, the present study played an exploratory role. Thus, a larger variety of preceding contexts, such as $/ \mathrm{u} /$, would allow for a more accurate view; however, it would make the data gathering session too exhaustive for the participants. One suggestion for further research is the inclusion of consonants as preceding contexts. In order not to make the data gathering sessions too long, only problematic contexts could be included in the following context.

The present study provided hierarchies and clues for the design of perceptual training tasks meant to avoid palatalization. However, because such tasks have not been actually tested, their design and implementation should be investigated in further research.

A second limitation concerns the lack of statistical tests on the combination of contexts. Further investigations can be carried out by using more sophisticated statistical procedures with the data already gathered.

Finally, in order to include enough tokens of each context, the instrument selected for data gathering was a reading test. The data of the present study could be compared with data from a free speech test 
to verify whether palatalization is equally produced in a more natural situation.

\section{Notes}

1. / $\mathrm{a} /$ and / / / are placed together because they are usually confused by Brazilian learners of English and used interchangeably.

2. Statistical tests were not run on the data due to the small number of productions.

\section{References}

Albano, E. C. (1999). O português brasileiro e as controvérsias da fonética atual: pelo aperfeiçoamento da fonologia articulatória. D.E.L.T.A., 15, Número Especial, $23-51$.

Albano, E. C. (2001). O gesto e suas bordas: esboço de fonologia acústico-articulatória do português brasileiro. Campinas: Mercado de Letras.

Baptista, B. O. \& Silva Filho, J. L. A. (2006) The influence of voicing and sonority relationships on the production of English final consonants. In B. Baptista \& M. A. Watkins (Eds), English with a Latin Beat. Studies in Portuguese/Spanish-English interphonology (pp.73-90). Amsterdam: John Benjamins.

Bettoni-Techio, M. \& Koerich, R. D. (2006). Palatalization in Brazilian Portuguese/ English interphonology. Revista Virtual de Estudos da Linguagem, 4, (7).

Bettoni-Techio, M. (2005). Production of final alveolar stops in Brazilian Portuguese/ English interphonology. Unpublished master's thesis. Universidade Federal de Santa Catarina, Florianópolis.

Bettoni-Techio, M \& Koerich, R. D. (2008). Perceptual training on the pronunciation of /s/-clusters in Brazilian Portuguese/English interphonology. In A. S. Rauber, B. O. Baptista, \& M. A. Watkins (Eds), New Sounds 2007: Proceedings of the Fifth International Symposium on the Acquisition of Second Language Speech. (pp. 5366). Florianópolis: Universidade Federal de Santa Catarina.

Bettoni-Techio, M., Rauber, A. S., \& Koerich, D. (2007). Perception and Production of Word-Final Alveolar Stops by Brazilian Portuguese Learners of English. In: Proceedings of Interspeech 2007 (pp. 2293- 2296). Antwerp, Belgium. 
Cristófaro-Silva, T. (2002). Fonética e Fonologia do Português: roteiro de estudos e guia de exercícios ( $6^{\mathrm{a}}$. Edição). São Paulo: Editora Contexto.

Eckman, F. R. (1991). The structural conformity hypothesis and the acquisition of consonant clusters in the interlanguage of ESL learners. Studies in Second Language Acquisition, 13, 23-41.

Eckman, F. R. \& Iverson, G. K. (1997). Pronunciation Difficulties in ESL: Coda Consonants in English interlanguage. In Yavas, M. (Ed.), First and Second Language Phonology (pp. 251-266). San Diego: Singular Publishing Group, Inc.

Giegerich, H. J. (1992). English Phonology: An Introduction. Cambridge University Press.

Hansen, J. G. (2001). Developmental sequences in the acquisition of English L2 syllable codas - A preliminary study. Studies in Second Language Acquisition, 26, 85-124.

Hooper, J. B. (1976). An Introduction to Natural Generative Phonology. New York: Academic Press.

Jackson, H. (1980). Analyzing English - An Introduction to Descriptive Linguistics. Oxford: Pergamon Press.

Kluge, D. C. (2004). Perception and Production of final Nasal by Brazilians Learners of English. Unpublished master's thesis. Universidade Federal de Santa Catarina, Florianópolis.

Koerich, R. D. (2006). Perception and Production of vowel paragoge by Brazilian EFL students. In: B. O. Baptista, M. A. Watkins (eds.), English with a Latin Beat: Studies in Portuguese/Spanish-English Interphonology (pp. 91-104). Amsterdam: John Benjamins.

Laver, J. (1994). Principles of Phonetics. Cambridge: Cambridge University Press.

Marchal, A. and Hardcastle, W. J. (1993). ACCOR: Instrumentation and database for the cross-language study of coarticulation.Language and Speech - Special Issue on Coarticulation, 36 (2/3), 137-153.

Modarresi, G. , Sussman, H., Lindblom, B. and Burlingame, E. (2004). An acoustic analysis of the bidirectionality of coarticulation in VCV utterances. Journal of Phonetics, 32, (3), 291-312. 
Monaretto, V. O., Quednau, L. R., \& Hora, Dermeval. (1994).As consoantes do português. In Bisol, Leda. (Ed.), Introdução a estudos de fonologia do português brasileiro. Porto Alegre: EDIPUCRS..

Recasens, D. (1987). An acoustic analysis of V-to-C and V-to-V coarticulatory effects in Catalan and Spanish VCV Sequences. Journal of Phonetics, 15, 299-312.

Recasens, D. (1990). The articulatory characteristics of palatal consonants. Journal of Phonetics, 18, 267-280.

Recasens, D., Farnetani, E., Fontdevilla, J., \& Pallarès, M. D. (1993) An electropalatographic study of alveolar and palatal consonants in Catalan and Italian. Language and Speech - Special Issue on Coarticulation, 36 (2/3), 213234.

Silveira, R. (2004). The influence of instruction on the perception and production of English word-final consonants. Unpublished doctoral dissertation. Florianópolis: Universidade Federal de Santa Catarina.

Silveira, R. C. P. (1986). Estudos da Fonologia Portuguesa. São Paulo: Editora Cortez.

Wise, C. M. (1957). Introduction to Phonetics. N. J. : Prentice Hall.

Wolfram, W., \& Johnson, R. (1982). Phonological analysis: focus on American English. Washington, DC: Harcourt Brace Jovanovich, Inc.

Zsiga, E. (2000). Phonetic alignment constraints: consonant overlap and palatalization in English and Russian. Journal of Phonetics, 28, 69-102.

Yavas, M. (1994). Final stop devoicing in interlanguage. In M. Yavas (Ed.) First and Second language Phonology (pp. 267-282). San Diego, CA: Singular Publishing Group, Inc. 


\section{APPENDIX A}

\section{SENTENCE READING TEST SAMPLE}

Preceding context: /i, E, A/,$\Lambda$, al , o/

Following context: /i, E, o, p, b, t, d, k, g, s, z, f, v, h, tS dZ, I, $\mathrm{m}, \mathrm{n}, \mathrm{O} /$

\begin{tabular}{|l|l|}
\hline $\mathrm{t}$ & $\mathrm{d}$ \\
\hline i $\mathrm{m}$ & i $\mathrm{m}$ \\
He has to eat more. & They need my help. \\
\hline i $\mathrm{i}$ & i $\mathrm{i}$ \\
They never greet each other. & I read easy books. \\
\hline i $\varepsilon$ & i $\varepsilon$ \\
They eat eggs. & They need eggs. \\
\hline io & io \\
The meat offer is low. & We need oranges. \\
\hline i p & i p \\
They eat peaches. & They need pencils. \\
\hline i b & i b \\
Monkeys eat bananas. & They need better houses. \\
\hline i $\mathrm{k}$ & i $\mathrm{k}$ \\
Bunnies eat carrots. & Children need cooperation. \\
\hline i g & i g \\
This street garage is empty. & My parents breed garlic. \\
\hline i d & i d \\
I eat delicious food. & High speed destroyed her car. \\
\hline i t & i t \\
I eat turkey. & They need total coverage. \\
\hline
\end{tabular}

